\title{
Evaluation of the presence of coliform in bottled drinking water, released in Sari in 2016
}

\author{
Zabihollah Yousefi $^{1}$, Alireza Ala $^{2^{*}}$, Masoumeh Eslamifar ${ }^{1}$ \\ ${ }^{1}$ Department of Environmental Health Engineering, School of Public Health, Mazandaran University of Medical Sciences, Sari, Iran \\ ${ }^{2}$ Student Research Committee, School of Public Health, Mazandaran University of Medical Sciences, Sari, Iran
}

\begin{abstract}
Background: Today, bottled water is used in many countries of the world due to its relatively low cost, better taste, ease of access and low levels of impurities. In unfavorable conditions, the maintenance of microorganisms due to hydrophobicity and adherence to bottles and as a result of increased lipolytic activity can lead to undesirable changes in color, taste and odor, and in cases of more severe load, microbial contamination may cause unhealthy water and flooding. In this study, the presence or absence of coliform in a number of bottled water brands was examined.

Methods: The microbial quality of 10 markers of bottled water present in the market of Sari that was randomly selected from each mark and three samples was examined. The samples were analyzed using the coliform - presence/absence (P-A) test. The results were compared with national standards and the World Health Organization (WHO) guidelines. Data were analyzed using SPSS version 24 and EXCEL. Results: Samples showed no microbial contamination Also, coliform and fecal coliforms were not observed in any of the samples. Finally, it was revealed that all cases were in accordance with national standards and WHO guidelines.

Conclusion: Increasing the health indexes of places, food supply and distribution centers, and maintaining health conditions and measures that have been considered especially in the recent years on the health of bottled water, have greatly reduced the problems.

Keywords: Taste, Drinking water, Bacteria, World Health Organization, Bottled water

Citation: Yousefi Z, Ala A, Eslamifar M. Evaluation of the presence of coliform in bottled drinking water, released in Sari in 2016. Environmental Health Engineering and Management Journal 2018; 5(3): 181-186. doi: 10.15171/EHEM.2018.25.
\end{abstract}

\section{Article History:}

Received: 2 July 2018

Accepted: 26 August 2018

ePublished: 15 September 2018

\section{Introduction}

Today, bottled water is used in many countries of the world due to its relatively lower cost, better taste, ease of access and low levels of impurities. It is also used in areas where drinking water is not available in a good quality and water purification facilities are not available. The use of bottled water in different parts of the world is evident as a result of people's demand for safe and healthy water (1). Given that raw water resources are increasingly used to meet the needs of industries, agriculture and growing populations, the shortage of available and safe drinking water has become a problem in many parts of the world. As a result of major water and food crises, there will be a great concern about the health and quality of drinking water (2). In developing countries, the most important cause of the use of packaged water is the prevention of contamination with diseases caused by contaminated water (3). Preserving the safety and quality of drinking water is always a major public health problem. Waterborne diseases are one of the most important health problems in developing countries (4). In a poll released by the distribution of 760 questionnaires among 352 women and 308 men from March 2010 to June 2011, 98.6\% of the respondents stated that they used bottled mineral water (5). In unsuitable storage conditions, microorganisms can be hydrophobic and bind to bottles and, as a result of increased lipolytic activity, can lead to undesirable changes in color, taste ,and odor, and in cases of more severe microbial contamination, it may cause unhealthy water and even an outbreak of microbial infections (6). The probability of contamination of packaged waters in different stages of the production process, including the provision of raw materials, maintenance and distribution (1). Water contamination in the source is caused during bottling or under unsuitable storage conditions. Therefore, compliance with the sanitary regulations during packaging 
and receiving bottled water, the care and cleaning of the equipment and the proper maintenance of the packaging components is of great importance (7). According to WHO, drinking water sources are categorized into two groups: protected and unprotected. The bottled water is categorized in the second group (8). In cases of crisis and shortage of drinking water supplies, the trade of packaged water increases in many countries. On the other hand, the inability of private and public networks to ensure the safety and microbial conditions of water has led to many cases in many countries, and people use bottled water for their convenience and safety. According to the report of WHO, in some parts of the world, water bottles need more control because they are stored at higher temperatures and for longer periods than water distribution networks (9). According to the standards by WHO for bottled water, in drinking water consumed by human beings, the total number of coliforms and fecal coliforms in $100 \mathrm{~mL}$ of the sample should be zero (8). According to the statistics, the world's average packaged water consumption has increased by an average of $7 \%$ per year. The high proportion of packaged water has resulted in the production of this product at smaller scale by producers with few facilities, regardless of sanitary methods, packaging water that cannot guarantee the safety and health of this product (10). Although currently, the main consumers of this type of water are European countries, the trend of increasing consumption in Asia and the Pacific is faster. This increase is reported to be about $15 \%$ (11). Several sources have shown that bottled water is not sterile and may contain various pathogens such as coliform (12). Escherichia coli is used as an indicator of fecal contamination of water. Because they are commonly found in human and animal stools (10). The bacteria of the coliform group are from the Enterobacteriaceae family of different genes and species. The shape of these bacteria is a rod that can ferment lactose at $35^{\circ} \mathrm{C}$ for 48 hours and produce acid and gas (13). Although intestinal bacteria are not harmful to humans, but their presence is an indication of the presence of pathogenic bacteria, viruses and protozoa (14). Bottled drinking water is considered as a food and is subject to food standards. In Iran, all the factories producing this product are operating under the supervision of the country's health organizations, and comply with special regulations during production (1). Many studies have been done in this area around the world. In a study titled Bacterial Quality of Bottled Mineral Water in Hungary, it was revealed that the level of the coliforms and pathogens of the bacteria exceeds the standard (15). Also, a study conducted by Zamberlan da Silva et al in Brazil, showed that the microbial quality of urban water is far better than bottled water (6). In Iran, various studies have been done on the quality of bottled water. In a study conducted by Alimohammadi et al, coliforms were found in about $12 \%$ of the samples and all specimens lacked bacteria in the thermophilic coliform group (16). In a study by Eslami et al in Qazvin, the microbial characteristics of the samples were in accordance with the national standards (17). The national standard of Iran, No. 6694, defines bottled water as drinking water packaged in containers that naturally contains or is added salts. It can be naturally added to or added to carbon dioxide gas. It is not allowed to add any other substances, such as sweeteners and flavors. The microbial characteristics of the packaged drinking water should be in accordance with the Iranian national standard No. 6262. Packaged drinking water should be packed in healthy conditions in accordance with Iranian national standard No. 6305 (18). Due to discrepancies between various studies, and given that many travelers and tourists travel to the city of Sari in different seasons, on the other hand, the abundance of bottled water in food stores and the increasing use of packaged water in Mazandaran province, the importance of the health of bottled water should be always sustained. In this study, the microbial quality of the bottled water at present Currently and in the period, was studied in a number of bottled water brands. The aim of this study was to determine the overall presence of the coliform in bottled drinking water supplied in the city of Sari, as well as provide information on the safety of packaged drinking water available in the market and to determine the microbiological quality of several brands of bottled drinking water in 2017.

\section{Materials and Methods}

This is a descriptive-cross-sectional study in which and the actual conditions of supply of bottled water at supermarkets in the city of Sari were considered. In this study, 10 brands of bottled water in the city of Sari were randomly selected, and of each brand, 3 samples were randomly purchased and transmitted to the microbiological laboratory of the Department of Environmental Health Engineering School of Health, Mazandaran University of Medical Sciences, Sari. Of 30 bottled water samples, 15 samples were mineral water and 15 samples were drinking water. One of the simple methods for identifying coliforms in water is the existence of a lack of coliform. This method makes it possible to test a large number of water samples simultaneously. The basis of this method is to evaluate the microbial quality of a $100 \mathrm{~mL}$ volume of the sample in the appropriate culture medium, which results in the qualitative information on the presence or absence of coliforms. Considering that there should be no coliforms in $100 \mathrm{~mL}$ of drinking water sample, This field experiment provides background analysis for identification and isolation of other indices (fecal coliforms, Aeromonas, Staphylococcus, Pseudomonas, Streptococcus and Clostridium) in the same qualitative way. Another advantage of this method is the possibility of testing a large number of samples in less time. First, the powdered P-A growth medium was dissolved in water (without heating). Since the sample was $100 \mathrm{~mL}$, the growth medium was made three times the 
concentration (Figure 1). Then, $50 \mathrm{~mL}$ of the medium was poured into $250 \mathrm{~mL}$ bottles (Figure 2).

And autoclaved at $121^{\circ} \mathrm{C}$ for 12 minutes. (The total sterilization time was 30 minutes or less). The final $\mathrm{pH}$ was $6.8 \pm 0.2$ after autoclaving. Samples were encoded according to the sample brand and number. The codes based on each brand include CH, D, O, CHL, N, T, P, G, OK and $S$, which were numbered from 1 to 3 for each brand. $100 \mathrm{ml}$ of the sample was transferred into a P-A culture medium in a $250 \mathrm{~mL}$ bottle and the bottle was thoroughly left 5 seconds to mix the sample and the medium (three times the concentration). Water samples were transferred into the medium alongside the flame at an appropriate distance (Figure 3).

Three samples of each brand of bottled water were cultivated; the samples were then incubated at temperature of $35 \pm 0.5^{\circ} \mathrm{C}$. A after 24 to 48 hours, production of acid (yellow color in the medium followed by the fermentation of lactose) was investigated. Data were analyzed using SPSS version 24 and EXCEL.

\section{Results}

By shaking the bottle, in all samples, except for one case, there was no change in color and gas production. This represents a negative result of probabilistic testing in other cases. A weak color change was observed in the P-A medium which had been inoculated into the BGLB environment (Figure 4). And was placed in an autoclave for $48 \mathrm{hr}$ at temperature of $35 \pm 0.5^{\circ} \mathrm{C}$. No gas production was observed in the BGLB environment over a 48-hour period, and the absence of coliforms in the water sample was confirmed. The result was expressed as a negative reaction of P-A test for total coliforms in $100 \mathrm{~mL}$ samples. Total coliform and fecal coliform were not found in any of the samples. According to Table 1, based on the performed microbial tests, the geometric mean of total coliform and fecal coliform bacteria in $100 \mathrm{~mL}$ was zero $(P=0.001)$.

Table 2 lists the microbiological standards for packaged drinking water according to the standards of the National Institute for Standardization of Iran No. 1053, 6694, 1011, 6267 and the World Health Organization (WHO) for the quality of drinking water, the Food and Drug Administration (FDA) The United States Environmental Protection Agency (US EPA) and the International Bottled Water Association (IBWA).

\section{Discussion}

According to the results of the P-A tests and in compliance with Iranian National Standard No. 3759, in relation to the bacteriological characteristics of packaged drinking water, the optimum level and the maximum permissible total coliform in packaged water was set at zero in $100 \mathrm{~mL}$, and raccording to the WHO guidelines, the microbial quality of packaged drinking water supplied in Sari was within the standard range. However, the results of the tests led to the absence of coliform in bottled water, but microorganisms are always capable of growing on suitable growth sites and bottled water can increase the number of microorganisms that can survive. Inappropriate disinfection, improper storage conditions, the problem of the bottled water production process in the factory, and the presence of microbial contamination in the source of bottled water, may cause undesirable changes in color and taste, and in the more severe cases, an increase in the burden of

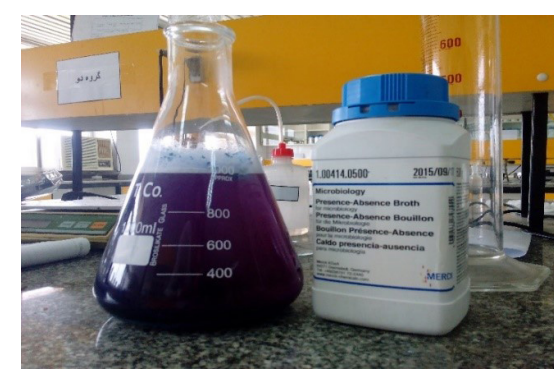

Figure 1. Preparation of P-A growth medium.

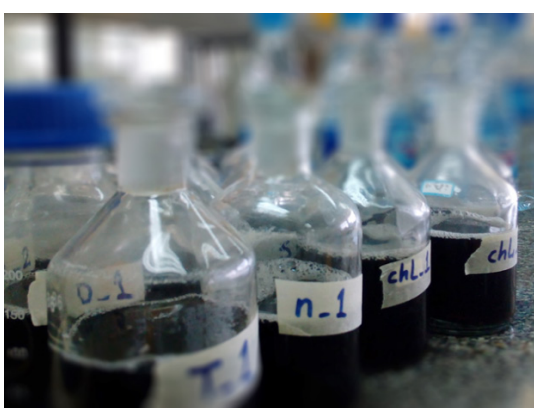

Figure 2. Preparation of P-A growth medium.

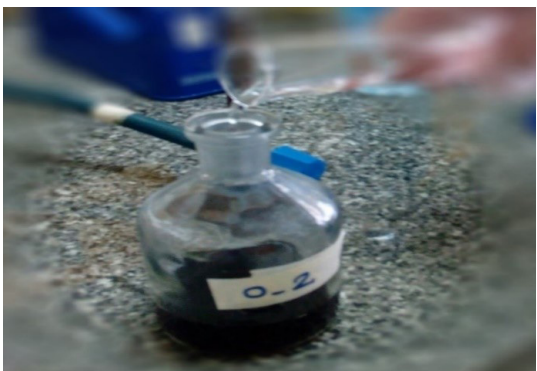

Figure 3. Transfer of water samples into the growth medium

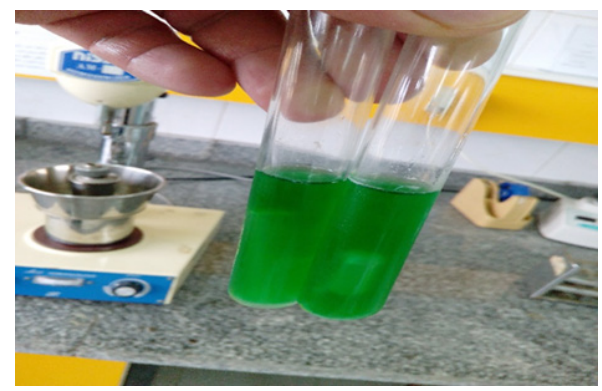

Figure 4. Inoculation in BGLB Growth medium. 
Table 1. Test results

\begin{tabular}{|c|c|c|c|c|c|c|c|c|c|c|}
\hline Sample Code & S-1 & $\mathrm{CH}-1$ & D-1 & $0-1$ & CHL-1 & $\mathrm{N}-1$ & T-1 & P-1 & G-1 & OK-1 \\
\hline MPN/100 mL & Negative & Negative & Negative & Negative & Negative & Negative & Negative & Negative & Negative & Negative \\
\hline Sample Code & S-2 & $\mathrm{CH}-2$ & D-2 & $0-2$ & CHL-2 & $\mathrm{N}-2$ & $\mathrm{~T}-2$ & P-2 & G-2 & ОК-2 \\
\hline MPN/100 mL & Negative & Negative & Negative & Negative & Negative & Negative & Negative & Negative & Negative & Negative \\
\hline Sample Code & S-3 & $\mathrm{CH}-3$ & D-3 & $0-3$ & CHL-3 & $\mathrm{N}-3$ & $\mathrm{~T}-3$ & P-3 & G-3 & OK-3 \\
\hline MPN/100 mL & Negative & Negative & Negative & Negative & Negative & Negative & Negative & Negative & Negative & Negative \\
\hline
\end{tabular}

Table 2. Microbiological standards of packaged drinking water

\begin{tabular}{|c|c|c|c|c|c|}
\hline Features & Iranian Standard & WHO (GV) & FDA (SOQ) & EPA (MCL) & IBWA (SOQ) \\
\hline Total coliforms (MPN/100 mL) & Negative & Negative & $2.2>(\ln 100 \mathrm{~mL})$ & Negative & Negative \\
\hline Fecal coliforms (MPN/100 mL) & Negative & Negative & Negative & Negative & Negative \\
\hline
\end{tabular}

microbial contamination. Therefore, the observance of sanitary regulations during the production and packaging of bottled water, and the care and maintenance of the equipment and the proper maintenance of packaging compounds are of great importance.

In a study conducted by Eslami et al in Qazvin, the microbial characteristics of the samples were standard (17). A study conducted in Canada on cold water showed that $3.7 \%$ of the samples contained coliforms and $23.3 \%$ of 3460 samples contained more than 100 colonies of heterotrophic bacteria (19). In a study conducted in Jaipur, the results showed that $55 \%$ of the samples were inappropriate for consumption. This study showed that local brands of potable water packaged for human consumption are inappropriate (20). In a study on bottled water in Lebanon, fecal coliforms was negative in all samples, but total coliforms was positive in $18.8 \%$ of the samples (21). In a study conducted by Hosseini in 2010 and the first five months of 2011 on the microbial and chemical status of mineral water bottles and bottled water in the province of Sistan and Baluchistan, 210 samples of bottled water were made from 37 available brands and a microbiological test was performed indicating that only one case was infected with coliforms (5). In the study of Bharath et al on Trinidad Island in Venezuela, 18 of 344 bottled water samples coliform (22). In a study conducted in Greece in 2008 on the quality of the microbial quality of bottled water, bottled water was not approved for consumption because $83 \%$ of the samples contained coliform and $13 \%$ contained E. coli (23). In another study, the bacterial quality of bottled water in the southwest of Nigeria was investigated. In $26.7 \%$ of bottled water brands, the presence of chlorophyll in $100 \mathrm{~mL}$ of water was detected (24). In surveys conducted in different areas over the past years, in; some cases, a high percentage of coliform in the samples was observed. And some of the results corresponded to the standards of the law enforcement agencies. Also, in a study conducted in Milan in 2010 on the quality of bottled water springs, the fountain was considered unsuitable for human consumption. Because HPC in $85 \%$ of the samples, the standard was higher (25). In a study in Brazil on the levels of heterotrophic bacteria in several samples of bottled water; The HPC rate was reported high in the two brands, on the first day of analysis. This information shows the importance of examining the level of HPC in bottled water (26). It has been confirmed that HPC alone cannot directly relate to human health risk, although they can show some changes in water quality, which also requires further research. The presence of coliform and fecal coliforms in bottled water indicates the contamination and potential of the presence of pathogenic microorganisms (27). In a study of the quality of the microbiology of drinking water packaged in western Nigeria, fecal coliform was identified in a sample. The results showed poor quality of some samples of drinking water packed (28). In the study of Olayemi, $40 \%$ of the 81 specimens did not have a promising microbial quality (29). In a study by Oyedeji et al, in a total of six brands of bottled water, coliform and E. coli were detected (10). The lack of indicator bacteria in many drinking water brands can be a reason for using health methods to produce these products by the industry. The sanitary filling of drinking water bottles and the use of appropriate and sealed bottles will help prevent contamination of these products. In accordance with national and international standards No. 4403, the total number of coliforms in the final product should be zero MPN per $100 \mathrm{~mL}$, According to the results of this study, it can be said that all 10 brands of cold water tested in this study had no problems with coliform and E. coli.

\section{Conclusion}

According to the results of this study and some other studies, the number of coliforms in bottled water is much lower than in the past, and bottled water tested in this study were approved for microbial quality. Regarding the implementation of this research and obtaining good results in assessing the status of bottled water supplied in 
Sari The importance of improving the health indicators of food and food distribution and distribution centers and the impact of the intensification of planned measures on improving the health of bottled water, in particular during the recent years, can be recognized. And the results of this study can be used to educate the general public about the use and improvement of the condition of these types of water, as well as raise the level of public knowledge for better control and monitor this product; to be taken into consideration in future plans.

\section{Acknowledgments}

This article is the result of a research project titled " Evaluation of the presence of coliform in bottled drinking water, released in the city of Sari in 2016" with a code of 58.96, supported by the Student Research Committee, Department of Environmental Health Engineering, School of Public Health, Mazandaran University of Medical Sciences, Sari, The authors would like to gratitude the Student Research Committee and the Microbiology Lab of the Department of Environmental Health Engineering School of Health, Sari. (IR.MAZums.REC.96 .58),

\section{Ethical issues}

It is confirmed that this manuscript is the original work of the authors. It has not been published, nor is under review in another journal, and it is not being submitted for publication elsewhere.

\section{Competing interests}

The authors declare that they have no conflicts of interest.

\section{Authors' contributions}

All authors contributed equally and participated in the data collection, analysis, and interpretation. All authors critically reviewed, refined, and approved the manuscript.

\section{References}

1. Miranzadeh MB, Ehsanifar M, Iranshahi L. Evaluation of bacterial quality and trace elements concentrations in 25 brands of Iranian bottled drinking water. Am Eurasian J Agric Environ Sci 2011; 11(3): 341-5.

2. Khadadadi M, Oudi Q. Study of microbial and chemical status of mineral water and water supplied in the city of Birjand, Winter 2006. 10th National Conference on Environmental Health; 2007 Oct-Nov 30-1; Hamedan University of Medical Sciences, Hamadan; 2007. [In Persian].

3. Dehghani M, Hashemi H, Karamimanesh M. Evaluation of the chemical and microbial quality of bottled water distributed during disasters. Int J Health Syst Disaster Manage 2013; 1(2): 68-71. doi: 10.4103/2347-9019.128114.

4. Hammuel C, Udiba UU, Gauje B, Raplong HH, Batari ML. Bacteriological and physicochemical quality of hand-dug well water used for drinking and domestic purposes in Dareta Village, Anka, Nigeria. British Journal of Applied Science \& Technology. 2014; 4(7): 1119. doi: 10.9734/

\section{BJAST/2014/6965.}

5. Hosseini A, Bazrafshan A, Moein H, Saravani R. check the status of biological and chemical mineral water been distributed in Sistan and Baluchistan province in 1389 and the first 5 months of 2011. 14th National Congress On Environmental Health; 2011 Nov 1-3; Shahid Sadoughi University of Medical Sciences and Health Services, Yazd; 2011. [In Persian].

6. Zamberlan da Silva ME, Santana RG, Guilhermetti M, Filho IC, Endo EH, Ueda-Nakamura T, et al. Comparison of the bacteriological quality of tap water and bottled mineral water. Int J Hyg Environ Health 2008; 211(5-6): 504-9. doi: 10.1016/j.ijheh.2007.09.004.

7. Nunes Filho SA, Sant'Ana AS, Cruz AG. Commercialization conditions and practices influence the microbiological quality of mineral waters. J Food Prot 2008; 71(6): 1253-7.

8. World Health Organization. Guidelines for Drinking-water Quality. 4th ed. Geneva: WHO; 2011.

9. Amini H, Taghavi Shahri SM, Amini M, Ramezani Mehrian M, Mokhayeri Y, Yunesian M. Drinking water fluoride and blood pressure? An environmental study. Biol Trace Elem Res 2011; 144(1-3): 157-63. doi: 10.1007/s12011-011-90545 .

10. Oyedeji O, Olutiola PO, Moninuola MA. Microbiological quality of packaged drinking water brands marketed in Ibadan metropolis and Ile-Ife city in South Western Nigeria. Afr J Microbiol Res 2010; 4(2): 96-102.

11. Loloei M, Zolala F. Survey on quality of mineral bottled waters in Kerman city in 2009. Journal of Rafsanjan University of Medical Sciences 2011; 10(3):183-92. [In Persian].

12. Bartram J, Cotruvo J, Exner M, Fricker C, Glasmacher A. Heterotrophic plate count measurement in drinking water safety management: report of an Expert Meeting Geneva, 24-25 April 2002. Int J Food Microbiol 2004; 92(3): 241-7. doi: $10.1016 /$ j.ijfoodmicro.2003.08.005.

13. Rompre A, Servais P, Baudart J, De-Roubin MR, Laurent P. Detection and enumeration of coliforms in drinking water: current methods and emerging approaches. J Microbiol Methods 2002; 49(1): 31-54.

14. Kara E, Ozdilek HG, Kara EE. An investigation on physical, chemical, and bacteriological quality of municipally supplied and well waters of the towns and city centre in the province of Nigde, Turkey. Int J Environ Health Res 2004; 14(2): 151-6. doi: 10.1080/0960312041000209480.

15. Varga L. Bacteriological quality of bottled natural mineral waters commercialized in Hungary. Food Control 2011; 22(3-4): 591-5. doi: 10.1016/j.foodcont.2010.10.009.

16. Alimohammadi M, Askari M, Aminizadeh S, Dehghanifard E, Rezazadeh M. Evaluation of microbial quality of bottled water in Iran. J Environ Health Eng 2014; 1(2): 137-45. doi: 10.18869/acadpub.jehe.1.2.137. [In Persian].

17. Eslami A, Jamali HA, Naderi S. Comparative study of bottled water microbial and physicochemical quality with national standards and its label ( a case study in Qazvin City, Iran). Iran J Health Environ 2013; 6(2): 155-66. [In Persian].

18. Institute of Standards and Industrial Research of Iran. NO.6694. Water - Packaged (bottled) drinking waters - Specifications 1st Revision. Tehran: ISIRI;1997. [In 
Persian].

19. Warburton D, Harrison B, Crawford C, Foster R, Fox C, Gour L, et al. A further review of the microbiological quality of bottled water sold in Canada: 1992-1997 survey results. Int J Food Microbiol 1998; 39(3): 221-6.

20. Gangil R, Tripathi R, Patyal A, Dutta P, Mathur KN. Bacteriological evaluation of packaged bottled water sold at Jaipur city and its public health significance. Veterinary World 2013; 6(1): 27-30. doi: 10.5455/vetworld.2013.27-30.

21. Semerjian LA. Quality assessment of various bottled waters marketed in Lebanon. Environ Monit Assess. 2011; 172(14): 275-85. doi: 10.1007/s10661-010-1333-7.

22. Bharath J, Mosodeen M, Motilal S, Sandy S, Sharma S, Tessaro T, et al. Microbial quality of domestic and imported brands of bottled water in Trinidad. Int J Food Microbiol 2003; 81(1): 53-62. doi: 10.1016/s0168-1605(02)00193-9.

23. Armas AB, Sutherland JP. A survey of the microbiological quality of bottled water sold in the UK and changes occurring during storage. Int J Food Microbiol 1999; 48(1): 59-65.

24. Igbeneghu OA, Lamikanra A. The bacteriological quality of different brands of bottled water available to consumers in Ile-Ife, south-western Nigeria. BMC research notes 2014; 7:859. doi: 10.1186/1756-0500-7-859.

25. Liguori G, Cavallotti I, Arnese A, Amiranda C, Anastasi D, Angelillo IF. Microbiological quality of drinking water from dispensers in Italy. BMC Microbiol 2010; 10: 19. doi: 10.1186/1471-2180-10-19.

26. Falcone-Dias MF, Farache Filho A. Quantitative variations in heterotrophic plate count and in the presence of indicator microorganisms in bottled mineral water. Food Control 2013; 31(1): 90-6. doi: 10.1016/j.foodcont.2012.09.038.

27. Otterholt E, Charnock C. Microbial quality and nutritional aspects of Norwegian brand waters. Int J Food Microbiol 2011; 144(3): 455-63. doi: 10.1016/j. ijfoodmicro.2010.10.034.

28. Olaoye O, Onilude A. Assessment of microbiological quality of sachet-packaged drinking water in Western Nigeria and its public health significance. Public Health 2009; 123(11): 729-34. doi: 10.1016/j.puhe.2009.09.015 .

29. Olayemi AB. Microbial potability of bottled and packaged drinking waters hawked in Ilorin metropolis. Int J Environ Health Res 1999; 9(3): 245-8. doi: 10.1080/09603129973218. 